Информация об их состоянии содержится в измерениях яркости. Это матрицы измерений случайных величин. Оценивались их средние значения, выборочные дисперсии, характеризующие разброс (рассеяние) флуктуаций яркости, определялись их гистограммы.

По результатам обработки яркости цифровых изображений трех разрабатываемых теплозащитных покрытий двигателей твердого топлива установлено, что их средние значения яркости и их разброс незначительно отличаются друг от друга (110, 111, 116 и 27, 24, 22). Эта гипотеза подтверждается по критериям Стьюдента [6].

Выводы. Работоспособность разрабатываемых ракетных двигателей нового поколения из композиционных материалов, корпуса которых должны выдерживать высокие тепловые нагрузки, не может быть обеспечена известными внутренними теплозащитными покрытиями. Это задача решена путем отбора и исследования специальных современных материалов, оценки качества и контроля внутренних теплозащитных покрытий.

Данное внутреннее теплозащитное покрытие применяется при проектировании и изготовлении корпусов ракетных двигателей твердого топлива перспективных разработок ГП «КБ «Южное» им. М.К. Янгеля».

\section{Библиографические ссылки}

1. Беллами Л. Дж. Инфракрасные спектры сложных молекул / пер. с англ.; под ред. Ю.А. Пентина. Москва : Иностр. лит., 1963. 592 с.
2. Козис К.В., Потапов А.М., Манько Т.А. Эффективность применения эластомерных материалов для внутренних теплозащитных покрытий ракетных твердотопливных двигателей. Вісник УМТ імені I.М. Францевича. Київ. Вип. 1 (9). 2016. C. $70-73$.

3. Козис К.В., Манько Т.А., Потапов А.М., Суетова Н.И. Оценка температуры разрушения теплозащитных покрытий ракетных двигателей твердого топлива. Системне проектування та аналіз характеристик аерокосмічної техніки: зб. наук. праць. Дніпро. 2015. Т. 19. С. 73-79.

4. Козис К.В., Манько Т.А., Потапов А.М. Оценка возможности замены клеевого состава в структуре внутреннего теплозащитного покрытия и силовой оболочки корпуса при разработке двигателей твердого топлива. Людина $i$ космос: тези XVII Міжнародної молодіжної науково-практ. конф. (06-08 квітня 2015 р.). Дніпропетровськ. 2016. С. 292.

5. Манько Т.А., Гусарова И.А., Козис К.В. Теплозащитные покрытия в авиа-, ракетно-космической технике. Матер. ХІІІ-й Междунар. конф. «Стратегия качества в промышленности и образовании». Болгария, 2017. Т. 1. C. 106-107.

6. Манько Т.А., Гусарова И.А., Козис К.В. Контроль состояния визуально недоступных поверхностей технических объектов. Системные технологии: Региональный межвузовский сб. научных работ. Вып. 2 (109). Днепр, 2017. С. 87-94.

Надійшла до редколегії 5.06.2018 p.

УДК: $681.372+656.34$

\title{
ДОСЛІДЖЕННЯ ПОЛЯРИЗАЦІЙНОЇ СКЛАДОВОЇ СТРАТОСФЕРНОГО ШАРУ ЗЕМЛІ ЗА ДОПОМОГОЮ УЛЬТРАФІОЛЕТОВОГО ПОЛЯРИМЕТРА
}

А.С. Матющенко ${ }^{1}$, О. В. Збруцький ${ }^{1}$, Г.В. Сарибога ${ }^{1}$, П.В. Неводовський ${ }^{2}$, Т.А. Левченко ${ }^{1}$, О.В. Олійник ${ }^{1}$

${ }^{1}$ Начіональний технічний університет Украйни «КПІ», Київ, Украӥна,

${ }^{2}$ Головна астрономічна обсерваторія НАН України, Київ, Україна

Досліджено актуальне питання поляризаційної складової стратосферного шару Землі за допомогою ультрафіолетового поляриметра. Дана проблема с малодослідженою та потребує подальшого вивчення. У роботі наведено структурну та функціональну схеми приладу. Значну увагу приділено енергетичному розрахунку для оптичної частини приладу.

(c) Матющенко А.С., Збруцький О.В., Сарибога Г.В., Неводовський П.В., Левченко Т.А., Олійник О.В., 2018 
Ключові слова: ультрафіолетовий поляриметр, пікосупутник, поляризація, інтенсивність світла, озоновий шар, спектр світла.

The article is devoted to the study of the actual issue of the polarization component of the stratospheric layer of the Earth with the help of an ultraviolet polarimeter. This problem is little studied and needs further study. The paper presents the structural and functional diagrams of the device. Considerable attention is paid to the energy calculation for the optical part of the device.

Keywords: ultravioletpolarimeter, picosatellite, polarization, lightintensity, ozonelayer, spectrumoflight.

Исследован актуальный вопрос поляризационной составляющей стратосферного слоя Земли с помощью ультрафиолетового поляриметра. Данная проблема мало исследована и требует дальнейшего изучения. В работе приведены структурная и функциональная схемы прибора. Значительное внимание уделено энергетическому расчету для оптической части прибора.

Ключевые слова: ультрафиолетовый поляриметр, пикоспутник, поляризация, интенсивность света, озоновый слой, спектр света.

Мета. Загальною метою $\epsilon$ встановлення приладу на супутник, запуск на геоцентричну орбіту з метою отримання реальних вихідних даних, які будуть відображати значення змін поляризаційної складової ультрафіолетового випромінювання, відбитого від озонового шару Землі.

Необхідно створити структурну та функціональну схеми приладу, провести енергетичний розрахунок для оптичної частини пікополяриметра.

Новизна. Визначення поляризаційної складової стратосферного озонового шару Землі із застосуванням мікросупутника у світі ще не проводилися.

Результати таких НД у подальшому можуть буди використані для визначення екологічного стану навколишнього середовища України, в тому числі м. Києва та Київської обл.

Сучасний стан проблеми у світі та в Україні. Численні запуски ракет у космос, викиди хімічних заводів та багато інших видів людської діяльності призводить до зменшення товщини озонового шару нашої планети. За останні десятиріччя значно збільшилася кількість озонових 《дірок», а загальній вміст озону в атмосфері Землі зменшився щонайменше на 5-7 \%.

На сьогодні вже є карти озонового шару Землі, отримані різними способами. Переважно всі вони базуються на дослідженні поляризації повного спектра світла: від УФ ( $\approx 180$ нм) до інфрачервоного діапазону (більше 1000 нм). Озоновий шар майже повністю відбиває (на $97 \%$ ) лише УФ типу Б (200-300 нм). Досліджуючи саме цей діапазон хвиль, можна отримати реальну картину озонового шару Землі.
Вперше в Україні поставлено питання розробки ультрафіолетового поляриметра для вивчення фізичних характеристик аерозолю на висотах більше 30 км в атмосфері Землі із застосуванням супутника.

Основний зміст експерименту. Вхідною величиною для всього приладу i для його оптичної частини, як первинного перетворювача, є поляризоване УФ світло.

Систематично, в кожний оберт супутника навколо Землі, виконувати вимірювання поляризаційних компонентів дифузійно-відбитого сонячного випромінювання (рис. 1). Діапазон хвиль запропоновано брати від 200 до 350 нм. За умовами технічного завдання необхідно спроектувати ультрафіолетовий поляриметр 3 габаритними розмірами не більше $150 \times 150 \times 250$ мм.

Спираючись на умови ТЗ, проведено енергетичний розрахунок, наведений нижче.

Вхідні дані до розрахунку:

$\checkmark$ Фотоприймач General Purpose CsTe Photocathode R1228;

$\checkmark$ Спектральний діапазон 185-350 нм (max250 нм);

$\checkmark$ Діаметр катода $\mathrm{d}=8 \mathrm{mм}$;

$\checkmark$ Матеріал UV скло;

$\checkmark$ Анодна напруга $\mathrm{Ua}=100 \mathrm{~B}$;

$\checkmark$ Струм катода Imax $=1.2$ мкA; Іроб $=0.4$ мкA;

$\checkmark$ Чутливість $\mathrm{s}=10-20 \mathrm{мA} / \mathrm{BT}$;

$\checkmark$ Темновий струм $\operatorname{Imin}=1 * 10^{-12} \mathrm{~A}$;

$\checkmark$ Емність $\mathrm{C}=2.4 * 10^{-12} \Phi$;

$\checkmark$ Густина потужності УФ в межах 200-350 нм : $\rho=10^{-7}-10^{-3} \mathrm{BT} / \mathrm{M}^{2}$.

Розрахунок 


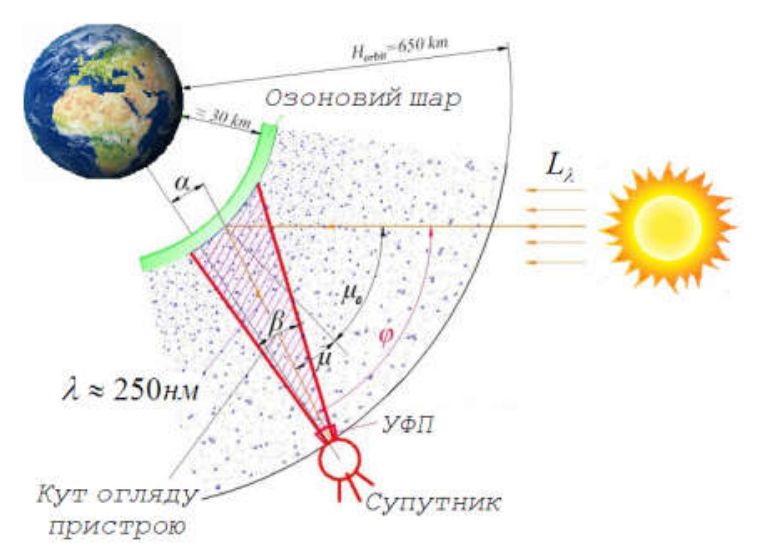

Рис. 1. Принцип роботи УФП

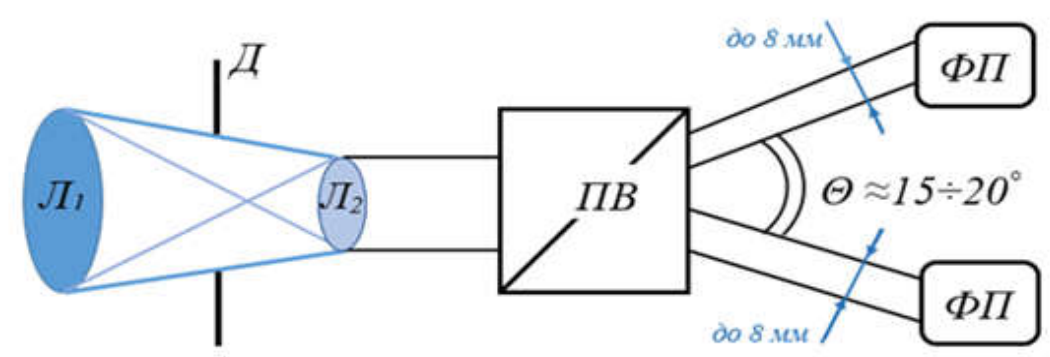

Рис. 2. Оптична схема УФП

$Л_{1}$ та $Л_{2}$ - лінзи Френеля, фокуси яких знаходяться в одній точці для отримання паралельного пучка світла; Д - діафрагма; ПВ - призма Воластона; ФП - фотоприймач

Враховуючи розміри пікосупутника, максимальний діаметр першої лінзи не має перевищувати 150 мм $=0,15$ м. Тоді площа лінзи:

$$
\begin{aligned}
& \mathrm{S}=\frac{\pi \mathrm{d}^{2}}{4}=\frac{3.14 \times 0.15^{2}}{4}=0.018 \mathrm{M} \\
& S N R_{\min }=10 \ln \frac{P_{g}}{P_{\mathrm{w}}}=10 \ln \frac{I_{q}^{2} R}{I_{\mathrm{m}}^{2} R}=20 \ln \frac{I_{g}}{I_{\mathrm{w}}}=20 \ln \frac{10}{1}=20 \mathrm{~d} \\
& I_{\mathrm{uv}}=s \times P_{\mathrm{uv}}=10 \times 10^{-3} \frac{A}{B m} \times 9 \times\left(10^{-10} \div 10^{-6}\right) B m=0.9 \times 10^{-11}+10^{-7} A \\
& I_{\text {min }}=9 \mathrm{nA} \approx 10 \mathrm{nA} \\
& I_{\max }=9 \times 10^{4} \mathrm{nA} \approx 10^{5} \mathrm{nA}
\end{aligned}
$$$$
P_{\mathrm{uv}}=\frac{1}{2} \times \rho \times S=\frac{1}{2} \times\left(10^{-7}+10^{-3}\right) \frac{B m}{M^{2}} \times 0.018 \mathrm{M}^{2}=9\left(10^{-10} \div 10^{-6}\right) B m
$$

Маємо :

Для перевірки вихідних даних на достовірність вираховуємо SNR (відношення сигналу до шуму):

$$
S N R_{\mathrm{max}}=10 \ln \frac{P_{q}}{P_{u}}=10 \ln \frac{I_{c}^{2} R}{I_{u}^{2} R}=20 \ln \frac{I_{c}}{I_{u z}}=20 \ln \frac{10^{5}}{1}=100 \partial \mathrm{\partial}
$$

Прийнято вважати, що для $\quad S N R_{\text {miм }}$ має бути не менше ніж 14-15 дБ, а нормального розпізнавання сигналу $\mathrm{SNR}_{\max }$ не менше ніж 80 дБ. Отримані 
значення потрапили в цей діапазон, тому приймаємо вихідні дані за істинне значення.

$$
\text { SNR }=[20 ; 100] \partial b
$$
втрат:

Враховуємо значення коефіцієнта

$$
k_{e}=\frac{k_{z}}{k_{m p}}
$$

де $k_{z}=2-$ запас потужності випромінювання;

$$
\begin{gathered}
P=\frac{P_{u v}}{k_{3}}=\frac{9\left(10^{-10}+10^{-6}\right)}{4}=2.25 \times 10^{-10} \div 2.5 \times 10^{-7} \mathrm{Bm} \\
I=\frac{I_{w v}}{k_{z}}=\frac{9\left(10^{-11}+10^{-7}\right)}{4}=2.25 \times 10^{-12}+2.5 \times 10^{-9} \mathrm{~A}
\end{gathered}
$$

SNR:

$$
\begin{aligned}
& 20 \ln \frac{2}{1}=14 \partial B \\
& 20 \ln \frac{250}{1}=110 \partial 5 \\
& \operatorname{SNR}=[14 ; 110] \partial 5
\end{aligned}
$$

Висновки до розрахунку

В ході розрахунку було отримано значення мінімального струму $\mathrm{I}=2,25$ пА, при цьому значення темнового струму фотоприймача $I_{\min }=1$ пА, що дає можливість використовувати фотоприймач General Purpose Cs-Te Photocathode R1228 для даного проекту. Для повної інформативності необхідно виконати

$$
k_{n p}=k_{1} \times k_{2} \times k_{n e}=0.9 \times 0.9 \times 0.8=0.65
$$
- коефіцієнт пропускання. Тоді маємо:

$$
k_{\varepsilon}=\frac{2}{0.65}=3.1 \text {, беремо } 4 \text {. }
$$

Значення потужності УФ та значення струму з урахуванням коефіцієнта втрат:

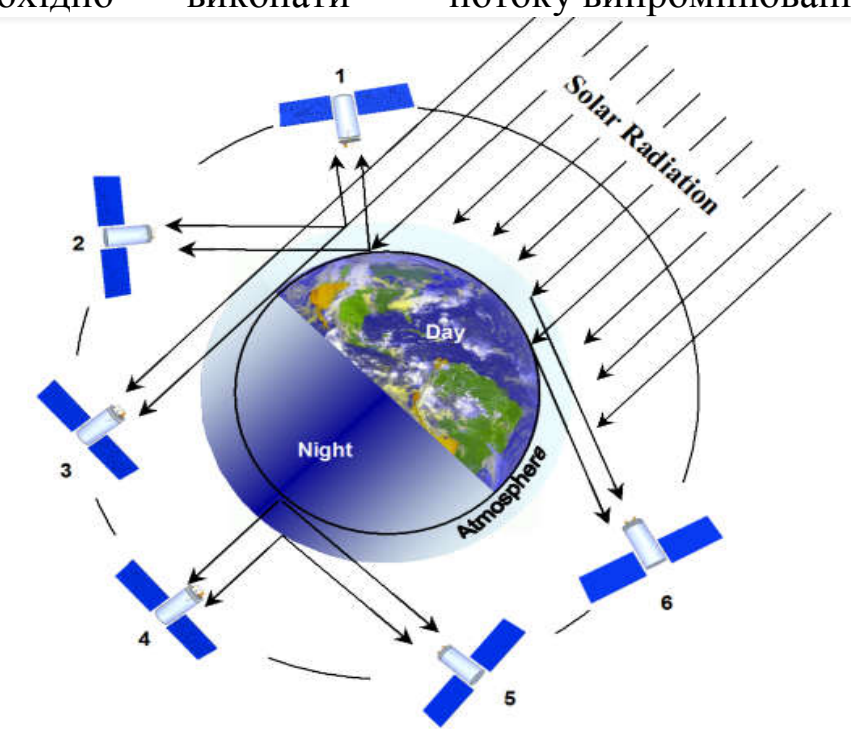

Рис. 3. Схема польоту супутника із УФП на борту

В загальному вигляді лінійна функція перетворення задається формулою: розрахунок поляризації залежно від орієнтації УФП у просторі (рис. 3).

Функція перетворення повинна мати лінійний вигляд. Діапазон вимірювання інтенсивності світла $\mathrm{I}=0-100 \mathrm{BT} / \mathrm{M}^{2}$. Вихідний сигнал має бути у вигляді постійної напруги $U= \pm 20$ В. Вимірюваною величиною $\epsilon$ інтенсивність світлового потоку випромінювання I [BT/ $\left.\mathrm{M}^{2}\right]$. 
де Y - вихідна величина (Вих.) вимірювального перетворювача, що залежить від ВB;

$\mathrm{X}$ - вимірювана величина (BВ);

$k_{0}$ - коефіцієнт $3 \mathrm{H}$;

$k_{1}-$ КП.

Для заданого вигляду ФП $k_{0}=0$.

Оскільки Вих. функціонально залежить від $\mathrm{BB}$, задамо загальну структурну схему:

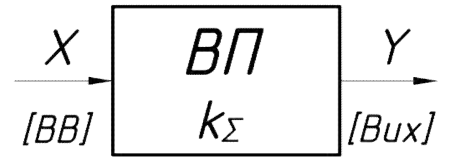

Рис. 4. Загальна структурна схема

\begin{tabular}{|c|c|c|c|c|c|c|c|}
\hline \multicolumn{8}{|c|}{$\epsilon$ таку структурну с } \\
\hline $\ln n_{3}$ & П & $I_{B \Pi}$ & ВП & 1 & $B /$ & $U$ & НП \\
\hline$\left[B T M^{M}\right]$ & $k_{n n}$ & & $k_{\text {втп }}$ & {$[A]$} & $k_{B n}$ & {$[B]$} & $k_{\text {нп }}$ \\
\hline
\end{tabular}

де ПП - первинний перетворювач, що складається 3 лінз, світлових фільтрів та призм, перетворює енергію поляризованого сонячного УФ світлового потоку $\left[\mathrm{BT} / \mathrm{M}^{2}\right]$ у два пучка енергії УФ світлового потоку,

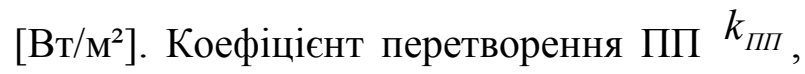
[1].

$$
I_{\text {ВП }}=k_{\text {ППГ }} \cdot I_{\text {ПП }}
$$

ВП - вторинний перетворювач, перетворює енергію УФ світлового потоку $\left[\mathrm{BT} / \mathrm{M}^{2}\right]$ в силу струму [А]. Коефіцієнт перетворення ВП $k_{B \Pi},\left[\mathrm{A} \cdot \mathrm{M}^{2} / \mathrm{BT}\right]$.

$$
I=k_{B \Pi} \cdot I_{B \Pi}
$$

ВЛ - вимірювальна ланка, яка перетворює силу струму [A] в електричний сигнал $\mathrm{U}$ [B]. ВЛ має коефіцієнт перетворення $k_{\text {вл }},[\mathrm{B} / \mathrm{A}]$.

$$
U=k_{B J} \cdot I
$$

НП - нормуючий перетворювач, який надає вихідному сигналу заданого вигляду. Коефіцієнт перетворення НП $k_{H \Pi}$, [1]

$$
U_{H}=k_{H \Pi} \cdot U
$$

Таким чином, сумарний коефіцієнт перетворення датчика:

$$
k_{\Sigma}=k_{\Pi \Pi \Pi} \cdot k_{B \Pi} \cdot k_{B \Pi} \cdot k_{H \Pi}
$$

Виходячи 3 діапазону вимірювання та діапазону значень вихідної напруги, КП повинен мати величину:

$$
k_{\Sigma}=\frac{20[B]}{100\left[B m / M^{2}\right]}=0,2\left[\frac{B \cdot M^{2}}{B m}\right]
$$

Опис приладу. Прилад буде складатися 3 чотирьох блоків: об'єктива, вузла призми, вузла фотоприймачів, електронного блока (рис. 4). Блок електроніки разом з блоком фотоприймачів призначений для перетворення двох складових поляризованого світлового потоку від оптичного блоку у відповідні електричні сигнали у вигляді послідовностей одноелектронних імпульссів, їх подальшого підсилення, реєстрації та перетворення його у цифрову форму (ТТЛсигнал), придатну для сприйняття сигналу засобами обчислювальної техніки з метою отримання результатів вимірювань, подальшої програмної обробки даних, їх накопичення та зберігання.

Поляризоване УФ світло поступає на вхід оптичної частини УФП, яка представлена на схемі у вигляді об'єктива, діафрагми, світлофільтра та поляризаційного елемента, де розкладається на два пучка УФ світла, які, у свою чергу, надходять на фотодіоди, звідти - на підсилювачі. Блок живлення 3'єднано 3 фотодіодами, термодатчиками та підсилювачами (рис. 3). До фотодіодів прикріплено термодатчики. Вихідні сигнали 3 підсилювачів та термодатчиків поступають в регістри і через комутатор направляються у процесор та пам'ять, також до комутатора приєднано таймер.

УФП має двоканальну структуру, яка не має рухомих елементів і складається з:

- оптичної частини (діафрагма, лінза, призма Воластона, світлофільтри);

- блока реєстрації сигналу та обробки інформації (фотоелектричні приймачі (фотодіоди), датчики температури і тиску, а також частотовимірювач (блок корекції сигналів), АЦП, ЦАП, управління УФП (бортовий обчислювач));

- блока передачі інформації на Землю (кодер, радіопередавач, радіоканал та ін.). 


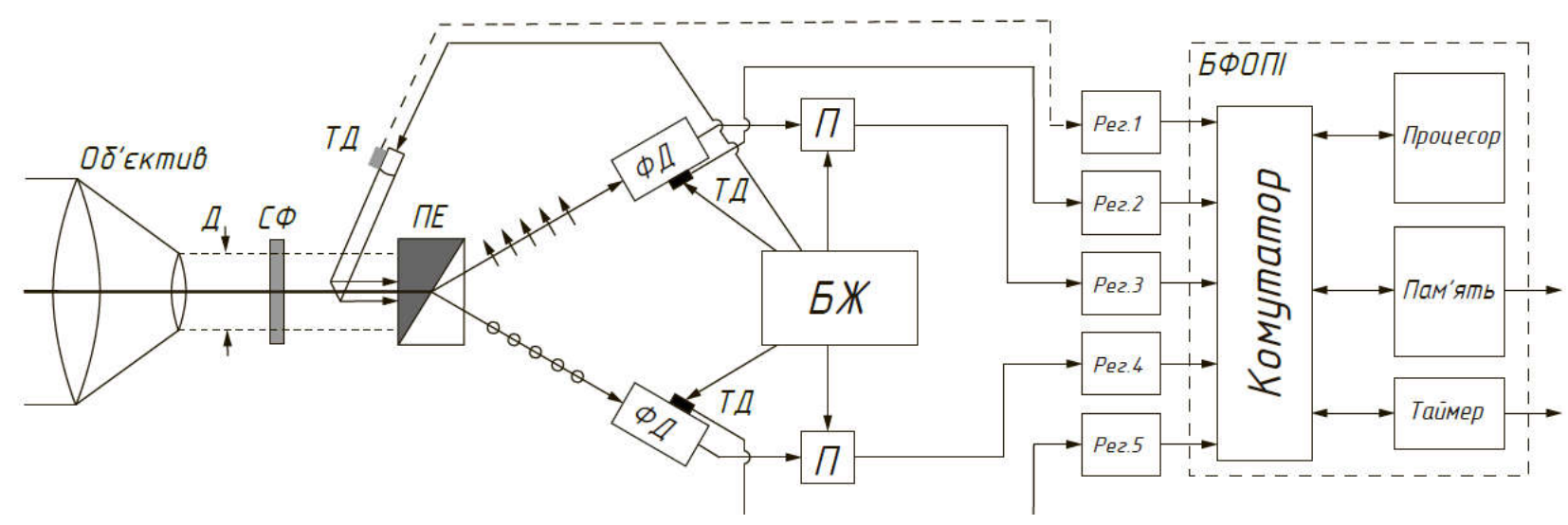

Рис. 6. Принципова схема УФП:

Д - діафрагма, СФ - світлофільтри, ПЕ - поляризаційний елемент, ТД - термодатчики, ФЕП - фотоелектронні помножувачі, БВН - блок високої напруги, > - підсилювач, ДІ дискримінатори імпульсів, БЖ - блок живлення, Рег. - регістр, БФОПІ - блок формування, обробки та передачі інформації

Масогабарити конструкції складатимуть близько 3-4 кг.

Конструкція ультрафіолетового поляриметра буде відповідати вимогам, що висовуються для мікросупутників типу YUZHSAT вагою до 50 кг. УФП розробляється як корисне навантаження під мікросупутник.

Висновки. У результаті проведеної роботи було розроблено електричну частину ультрафіолетового поляриметра на основі ультрафіолетового фотодіода. Було розроблено структурну та функціональну схеми приладу, проведено енергетичний розрахунок, базуючись на якому було обрано фотоприймач General Purpose Cs-Te Photocathode R1228 iз спектральним діапазоном 180-350 нм та максимумом чутливості $250 \mathrm{Hм.}$

Розрахунковим шляхом обгрунтовано працездатність конструкції. Виходячи 3 умови забезпечення діапазону вимірювання інтенсивності випромінювання від 0 до 100 $\mathrm{BT} / \mathrm{M}^{2}$ та діапазону зміни вихідного сигналу \pm 20 В, було забезпечено необхідний коефіцієнт перетворення. Температурна похибка коефіцієнта перетворення складає $0,08 \frac{\%}{{ }^{\circ} \mathrm{C}}$.

Розроблений вимірювальний перетворювач відповідає вимогам технічного завдання.

\section{Бібліографічні посилання}

1. URL: http://www.hamamatsu.com/res ources/pdf/etd/Phototubes_TPT1001E.pdf

2. Kostogryz N., Morozhenko A., Vidmacenko A., Nevodovkii P., Polarimetry and physics of atmospheric aerosol of the Earth. AGU Chapman Conf. on crossing boundaries in planetary atmocpheres: From Earth to exoplanetes., Annapolies, Maryland 24-28, June 2013. Abstracts. 2013. P. 22-23.

3. Morozhenko A.V., Vidmachenko A.P., Nevodovskyi P.V. Limited of polarimetry in determining of the Earth's atmospheric aerosol characteristics. 46th Lunar and Planetary Science Conference. March 16-20, 2015. Woodlands, Texas. LPI Contribution. No. 1832. P. 1031.

4. Morozhenko A.V., Vidmachenko A.P, Nevodovskyi P.V. Aerosol in the Upper Layer of Earth's. Kinematika Fizika Nebesnykh Tel. 2013. V. 29. No. 5. P. 243-256.

5. Morozhenko A.V., Vidmachenko A.P., Nevodovskiy P.V., Kostogryz N.M. On the efficiency of polarization measurements while studying aerosols in the terrestrial atmosphere. Kinematics and Physics of Celestial Bodies, 2014. V. 30. No. 1. P. 1121.

6. Nevodovskij P.V. Quvantakon and optimization of their parameters for astronomical observations. Kinematika I Fizika Nebesnykh Tel. No. 1. 09/2001. P. 283285. 
7. Nevodovskyi Ye.P., Vid'Machenko A.P., Morozhenko O.V., Nevodovskyi P.V., Syniavskyi I.I. The Ukrainian Youth Satellite: investigation of the Earth's aerosol stratum with the use of UV-polarimeter. Kosmichna Nauka I Tekhnologiya (ISSN 1561-8889). 2004. V. 10. No. 5/6. P. 27-32.

8. Ozone: Space Vision (Space monitoring of Earth Atmospheric Ozone) Copyright By Dr. Fred Ortenberg, ASRI, Technion November 2002. P. 17-18.

9. Nevodovsky P., Morozhenko A., Vidmachenko A., Geraimchuk M., Zbrutskyi A., Kureniov Yu., Sergunin V., Hirniak Yu., Ivakhiv O. Ultraviolet Polarimeter for Studying the Aerosol Component in the Earth Atmosphere. In Abstracts (Proceedings) of International Symposium "Atmospheric Radiation and Dynamics", Publishing Company. St Petersburg. Russia. 2013. P. 218.

10. Nevodovskyi P., Morozhenko O., Vidmachenko A., Ivakhiv O., Geraimchuk M., Zbrutskyi O. Tiny Ultraviolet Polarimeter for Earth Stratosphere from Space Investigation. Proceedings of $8^{\text {th }}$ IEEE International Conference on Intelligent Data Acquisition and Advanced Computing Systems: Technology and Applications (IDAACS'2015) Warsaw. Poland. Sept. 24-26. 2015. V.1. P. 2832.

11. Nevodovskyi P.V., Morozhenko A.V. Studies into stratospheric ozone layer from near-earth orbit utilizing ultraviolet polarimeter. In Acta Astronautica. 2009. V. 69. No 1. P. 54-58.

12. Travis L. Earth Observing Scanning Polarimetr. Long-Term monitoring of Global climate forcings and Feedbacks, Ed. by J. Hansen, W. Rossow, I. Fung. New York. 1992. P.40-46.

13. M. Geraimchuk, O. Genkin, O. Ivakhiv, Yu. Kureniov, O. Morozhenko, P. Nevodovskyi, S. Petrenko. Elements and Systems of Polarization Devices for Aerospace Investigation. Monography, EKMO. Kyiv (in Ukrainian). 2009.

14. Мороженко О.В. Методи i результати дистанційного зондування планетних атмосфер. Київ : Наукова думка, 2004. $647 \mathrm{c}$.

15. Неводовский П.В., Мороженко А.В., Неводовский Е.П., Гераимчук М.Д. Изучение характеристик аэрозоля стратосферы Земли методом ультрафиолетовой поляриметрии. Оптика и спектроскопия. 2009. 107. № 2. С. 231-23.

16. Мороженко О.В., Неводовський П.В., Видьмаченко А.П., Гераїмчук М.Д., Івахів О.В., Делець О.С. Про застосування ультрафіолетової поляриметрії для супутниковихдосліджень стратосферного аерозолю Землі. Украӥнський метрологічний журнал. 2014. № 2. C. 27-32.

Надійшла до редколегії 01.08.2018 p.

УДК 532.516

\title{
ЧИСЛЕННОЕ МОДЕЛИРОВАНИЕ ВЗАИМОДЕЙСТВИЯ НЕДОРАСШИРЕННОЙ СВЕРХЗВУКОВОЙ СТРУИ ГАЗА С ПЛОСКОЙ ПРЕГРАДОЙ
}

\author{
С.А. Николин, А.А. Приходько
}

Днепровский нащиональный университет имени Олеся Гончара, пр. Гагарина, 72, г. Днепр, 49010, Украина, е-mail: sergeynikolin@gmail.com

\begin{abstract}
Наведено результати чисельного моделювання на основі нестаціонарних усереднених за Рейнольдсом рівнянь Нав'є - Стокса взаємодії недорозширеного надзвукового струменя газу 3 плоскою пластиною, яка встановлювалася на різних відстанях від зрізу сопла. Результати розрахунків представлено у вигляді розподілів числа Маха і градіснта щільності в розрахунковій області, а також коефіціснтів тиску і тертя по поверхні пластини. Виконано порівняння результатів числових розрахунків з експериментальними даними.

Ключові слова: надзвуковий струмінь, плоска пластина, стрибок ущільнення, рециркуляційна зона.
\end{abstract}

The results of numerical modeling based on the nonstationary Reynolds-averaged Navier - Stokes 